\title{
COMPARAÇÃO DE TÉCNICAS ANALÍTICAS PARA A EXTRAÇÃO DE POTÁSSIO DE AMOSTRAS DE TECIDO VEGETAL COM ÁGUA E SOLUÇÕES ÁCIDAS CONCENTRADA E DILUÍDA
}

\author{
Alberto C. C. Bernardi ${ }^{1}$, Sílvia Harumi Oka² e Gilberto B. de Souza ${ }^{1}$ \\ ${ }^{1}$ Embrapa Pecuária Sudeste, Caixa Postal 339, 13560-970 - São Carlos, SP. E-mail: alberto@cppse.embrapa.br. \\ ${ }^{2}$ Química - UFSCar, São Carlos, SP.
}

\begin{abstract}
Resumo: O aprimoramento dos métodos analíticos faz com que a busca por novas tecnologias rápidas, exatas e de custo reduzido estejam constantemente sendo revistas e avaliadas. O objetivo deste trabalho foi comparar três formas de extração de K (decomposição nítro-perclórica, extração com água e extração com solução diluída de $\mathrm{HCl}$ ) de amostras da parte aérea de capim-tanzânia (Panicum maximum cv. Tanzânia) e de alfafa (Medicago sativa cv. Crioula). Os métodos de extração de $\mathrm{K}$ de amostras de tecido vegetal de capim-tanzânia e alfafa com solução ácida diluída ou com água apresentaram-se equivalentes ao método tradicional da decomposição nítro-perclórica e podem substituí-lo.
\end{abstract}

Palavras-chave: decomposição nitro-perclórica, HCL 1 mol L-1, extração com água.

\section{Introdução}

No metabolismo vegetal, o potássio $(\mathrm{K})$ atua na regulação do potencial osmótico celular e é muito importante no balanço das cargas negativas dos ácidos orgânicos dentro das células e no balanço dos ânions absorvidos pelas raízes. Este macronutriente é também ativador de várias enzimas e portanto requerido em numerosos processos metabólicos. O potássio é absorvido pelas plantas na forma catiônica $\left(\mathrm{K}^{+}\right)$e mantém-se nesta forma; ele não é metabolizado e forma complexos instáveis com ligações fracas [1]. Dessa forma, a quantidade da fração solúvel desse nutriente aproxima-se da fração total e pode ser um indicativo adequado do estado nutricional da cultura.

A análise química quantitativa de tecidos vegetais é um dos métodos utilizados para avaliar o estado nutricional das plantas, pois constitui uma medida direta da disponibilidade de nutrientes no solo, uma vez que os resultados correspondem à quantidade de nutrientes absorvida pelas plantas. Dessa forma, o teor de nutrientes nos tecidos vegetais reflete sua real disponibilidade no solo, porque existe relação direta entre o fornecimento de um nutriente pelo solo ou por um fertilizante e sua concentração na folha, e há relação também direta entre essa concentração e a produção da cultura. Tal técnica pode estar sujeita a limitações, tais como: épocas de amostragem, interpretação, contaminação da amostra, e deficiências e excessos de nutrientes. Apesar disso, é uma das melhores ferramentas disponíveis para avaliar o estado nutricional de plantas e para orientar programas de adubação, em associação com os resultados da análise de solo [2].

Para a determinação dos teores de K nas plantas, normalmente é necessária a transformação da matriz orgânica (amostra de tecidos vegetais) em uma forma inorgânica simples. O ácido nítrico é freqüen- 
temente usado nesse processo de decomposição devido sua manipulação simples, fácil purificação e eficiência na oxidação dos compostos orgânicos presentes na amostras biológicas [3].

Assim, o método tradicional utilizado para a decomposição do material vegetal é a via úmida. Mediante aplicação de uma solução concentrada de ácidos oxidantes (nítro-perclórica $-\mathrm{HNO}_{3}+\mathrm{HCLO}_{4}$ -, na proporção de $4: 1, v^{-1} \mathrm{v}^{-1}$ ), a matéria orgânica da amostra é totalmente oxidada. Os elementos a serem determinados são solubilizados em meio ácido, em formas inorgânicas simples e adequadas para análise [4].

No entanto, o constante aprimoramento dos métodos analíticos para tecidos vegetais faz com que a busca por novas técnicas de análise rápidas, exatas, de custo reduzido e baixo impacto ambiental sejam constantemente revistas e avaliadas. Por isso, nos últimos anos, pesquisas e trabalhos têm avançado significativamente nessa área, sendo que os procedimentos atualmente atendem a uma gama maior de elementos, as técnicas de determinação ganharam em agilidade e confiabilidade e também tornaram-se mais rápidas e precisas [5]. O método empregado, depende dos objetivos do estudo, dos elementos ou compostos a serem analisados e, inclusive, das potencialidades do laboratório [6], da simplicidade, do custo e da segurança operacional [7].

Dessa forma, existem métodos alternativos, que consistem na extração de $\mathrm{K}$ com água $[8,9,10]$ ou com solução ácida diluída, como o $\mathrm{HCl}$ na concentração de 1,0 mol.L ${ }^{-1}[5,7]$. Nesses métodos, apesar de não haver decomposição completa da matéria orgânica, o K e outros elementos são solubilizados; além disso, verifica-se alta correlação com outros métodos em que a decomposição da matéria orgânica é total [11]. No entanto, a literatura ainda é relativamente escassa com trabalhos sobre análise de elementos químicos sem o uso de digestão.

O objetivo deste trabalho foi comparar três formas de extração de K (decomposição nítro-perclórica, extração com água e extração com solução diluída de $\mathrm{HCl}$ ) de amostras da parte aérea de capim-tanzânia (Panicum maximum cv. Tanzânia) e de alfafa (Medicago sativa cv. Crioula).

\section{Material \& Métodos}

Foram utilizadas 300 amostras da parte aérea de plantas de alfafa e 101 amostras da parte aérea de plantas de capim-tanzânia, oriundas de experimentos com aplicação de doses de potássio. As amostras foram secadas em estufa de circulação forçada de ar, a $65^{\circ} \mathrm{C}$, moídas em moinho de facas de aço inoxidável do tipo Wiley, passadas em peneira de $1 \mathrm{~mm}$ e armazenadas em frascos plásticos.

Os procedimentos analíticos adotados foram baseados em Nogueira et al. [4] e Miyazawa et al. [7]. $\mathrm{O}$ extrato de $\mathrm{K}$ da decomposição nítro-perclórica foi obtido mediante adição de $6 \mathrm{~mL}$ da mistura de $\mathrm{HNO}_{3}+\mathrm{HCLO}_{4}$ na relação de 4:1 (v.v $\left.{ }^{-1}\right)$ a $500 \mathrm{mg}$ $( \pm 0,1 \mathrm{mg})$ de material seco. A extração com água constou do de aquecimento por $30 \mathrm{~min}$ em banhomaria a $80^{\circ} \mathrm{C}$ de $500 \mathrm{mg}( \pm 0,1 \mathrm{mg})$ de amostra em $25 \mathrm{~mL}$ de água ultrapura, seguida de agitação por 20 min e filtragem. O extrato da solução ácida diluída foi obtido da adição de $25 \mathrm{~mL}$ de $\mathrm{HCl}$ na concentração de 1,0 mol.L ${ }^{-1}$ a $500 \mathrm{mg}( \pm 0,1 \mathrm{mg}) \mathrm{de}$ matéria seca, seguida de aquecimento por $30 \mathrm{~min}$ em banho-maria a $80^{\circ} \mathrm{C}$, com posterior agitação por $20 \mathrm{~min}$ e filtragem em papel-filtro quantitativo de filtração rápida. Em todos os extratos a determinação do K ocorreu por fotometria de chama.

Para o estudo de concordância entre os métodos da decomposição nítro-perclórica, com água e com solução diluída de $\mathrm{HCl}$ utilizou-se a técnica de análise de correlação, o gráfico de dispersão e o ajuste de modelo por meio de regressão linear simples.

\section{Resultados \& Discussão}

A Figura 1 representa a comparação das três formas de extração de $\mathrm{K}$ de amostras de tecido vegetal da alfafa, pelos métodos da decomposição nítro-perclórica, e da extração com água e com solução extratora de $\mathrm{HCl}$ na concentração de 1,0

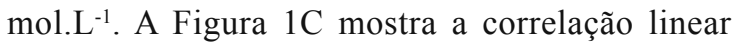
positiva e significativa entre o métodos com água e com $\mathrm{HCl}$ no intervalo de confiança de $95 \%(\mathrm{t}=$ 1,68). Quando comparados os dois métodos alternativos ( $\mathrm{HCl}$ e água) com a decomposição nítroperclórica obteve-se correlações lineares positivas 
com intervalos de confiança de $95 \%(\mathrm{t}=-2,81$ e $\mathrm{t}$ $=-4,01$, respectivamente; Figuras $2 \mathrm{~A}$ e $2 \mathrm{~B})$.
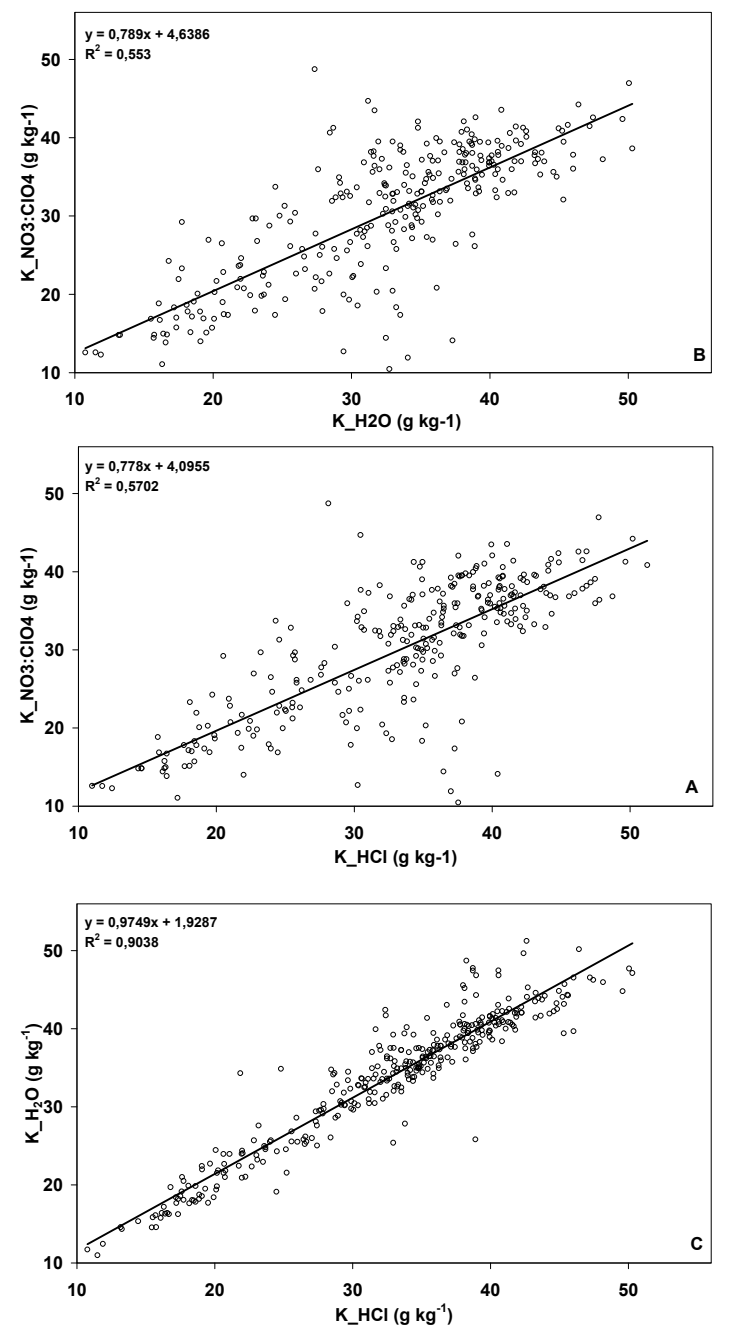

Figura 1. Comparação de três formas de extração de $\mathrm{K}$ (nítro-perclórica - $\mathrm{NO}_{3}: \mathrm{ClO}_{4}$, água $-\mathrm{H}_{2} \mathrm{O}$ e $\mathrm{HCl}$ na concentração de 1,0 mol. $\mathrm{L}^{-1}-\mathrm{HCl}$ ) de amostras da parte aérea de alfafa. $(n=300)$.

A Figura 2 representa a comparação de três formas de extração de $\mathrm{K}$ de amostras da parte aérea do capim-tanzânia, pelos métodos da decomposição nítro-perclórica, e da extração com água e com solução extratora diluída de $\mathrm{HCl}$. Os resultados seguiram a mesma tendência observada com a alfafa. Na comparação entre os métodos de extração com água e com solução diluída de $\mathrm{HCl}$ e a decomposição nítro-perclórica (Figuras 2A e
2B), não houve diferença estatística significativa, obtendo-se correlações lineares com intervalos de confiança de $95 \%(\mathrm{t}=1,064$ e $\mathrm{t}=0,389$, respectivamente). A melhor correlação foi obtida na comparação dos dois métodos alternativos (água e $\mathrm{HCl}$ - Figura 1C), da qual resultou correlação linear positiva e com diferença estatística não significativa, no intervalo de confiança de $95 \%$ ( $\mathrm{t}=$ 1,501).
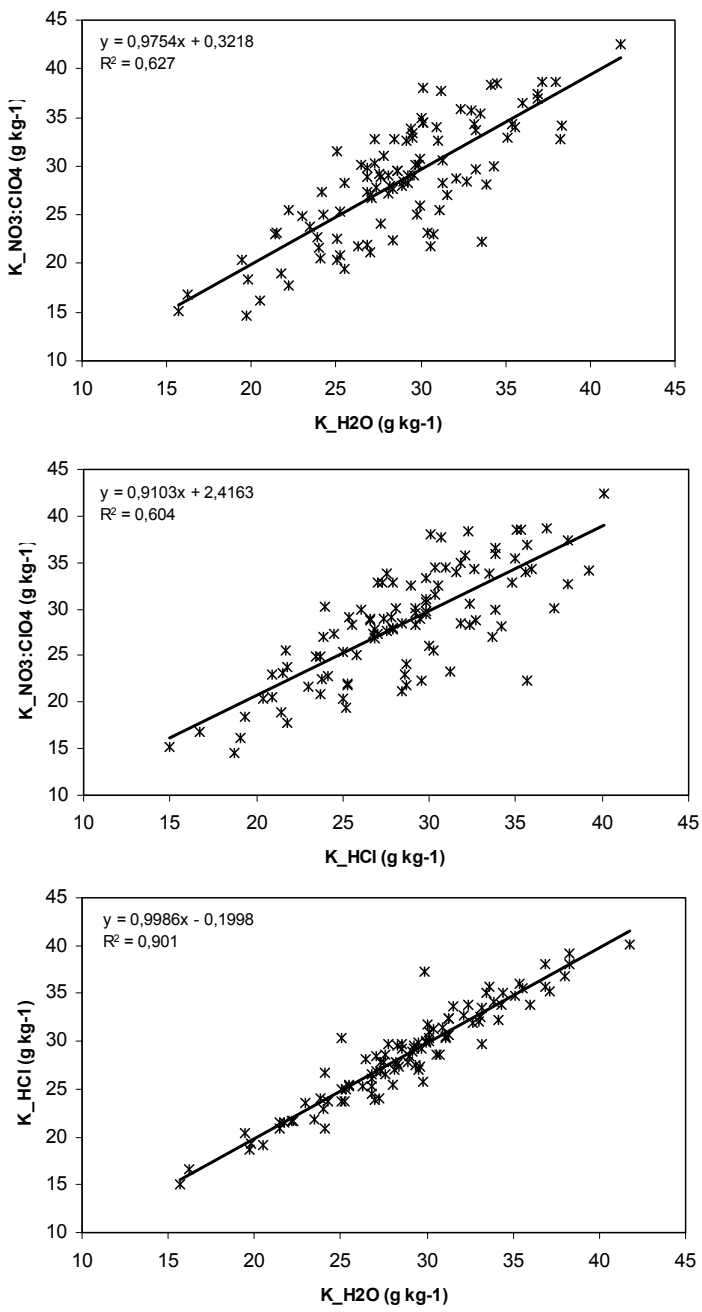

Figura 2. Comparação de três formas de extração de $\mathrm{K}$ (nítro-perclórica - $\mathrm{NO}_{3}: \mathrm{ClO}_{4}$, água $-\mathrm{H}_{2} \mathrm{O}$ e $\mathrm{HCl}$ na concentração de 1,0 mol. $\mathrm{L}^{-1}-\mathrm{HCl}$ ) de amostras da parte aérea de capim-tanzânia. $(n=101)$. 
Estes resultados confirmam a alta mobilidade nos tecidos do $\mathrm{K}$, uma vez que o cátion não participar de compostos orgânicos estáveis, acumulando-se no suco vacuolar, o que o torna facilmente lixiviável e de fácil translocação dentro da planta [1]. Heinrichs \& Malavolta [9] e Reissmann et al. [10], utilizando a água quente, também haviam demonstrado que é possível extrair quantidades substanciais de $\mathrm{K}$ de amostras de tecidos foliares de erva-mate (Ilex paraguariensis St. Hil). E Radomski \& Winiewski [8] observaram uma alta correção entre os teores solúveis e totais de K (91\%) extraídos de folhas de espinheira-santa (Maytenus ilicifolia (Schrad.) Planch).

Os resultados indicaram também que a extração sem digestão com $\mathrm{HCl}$ mostrou-se eficiente pela rapidez, simplicidade e elevado grau de solubilização. Carneiro et al [5] havia comparado a digestão nitro-perclórica e a extração em $\mathrm{HCl}$ $1 \mathrm{~mol} \mathrm{~L} \mathrm{~L}^{-1}$ obtendo altas solubilizações e correlações entre os métodos foram significativas para os elementos $\mathrm{K}, \mathrm{Mg}$ e $\mathrm{Al}$.

Provavelmente, a menor linearidade entre o método padrão (nítro-perclórico) e os métodos alternativos, nas amostras de ambas as espécies, ocorreu em virtude da formação do perclorato de potássio $\left(\mathrm{KClO}_{4}\right)$. Apesar de os percloratos de metais serem prontamente solúveis em água, o $\mathrm{KClO}_{4}$ é uma exceção e apresenta baixa solubilidade. Esse fator pode ter contribuído para a baixa recuperação deste elemento e assim influenciado a correlação com os procedimentos de extração em água e em solução de $\mathrm{HCl}[12,13]$, uma vez que recuperação do $\mathrm{K}$ nos métodos com $\mathrm{H}_{2} \mathrm{O}$ e $\mathrm{HCl}$ foram melhores do que a com digestão nitro-perclórica.

Apesar de o método da decomposição por via úmida com a mistura ácida nítro-perclórica ser o mais utilizado na dissolução de tecidos vegetais e de solubilizar quase totalmente a amostra, ele apresenta algumas limitações, como a emissão de vapores tóxicos, a necessidade de utilização de equipamentos especiais (capelas de gases e blocos digestores) e de reagentes de difícil aquisição (controlados pelo Ministério do Exército, pela Polícia Civil e pela Polícia Federal), além do perigo de explosão pelo emprego do ácido perclórico na forma oxidada e a quente. Já o método com solução de $\mathrm{HCl}$ diluído apresenta as vantagens de gerar menos poluição do ambiente (pela menor geração de gases e de vapores tóxicos ou corrosivos), de não requerer equipamentos específicos e de ser um método simples, rápido, de baixo custo e de fácil adaptação para análises de rotina. Porém, ele possui como limitação a extração parcial de alguns elementos, p. ex., Al, Fe e S [11].

Os resultados indicaram que o método de extração de $\mathrm{K}$ de amostras de tecido vegetal de capim-tanzânia e de alfafa com água quente pode ser utilizado, com a vantagem de ser uma extração que não gera resíduos tóxicos ao ambiente.

\section{Conclusões}

Os métodos de extração de $\mathrm{K}$ de amostras de tecido vegetal de capim-tanzânia e alfafa com solução ácida diluída ou eventualmente com água apresentaram-se equivalentes ao método tradicional da decomposição nítro-perclórica e podem substituí-lo.

\section{Agradecimentos}

Ao International Potash Institute - IPI pelo apoio financeiro na execução deste trabalho. 
Abstract: The improvement of analytical methods makes the search for new technologies fast, accurate and low cost are constantly being reviewed and evaluated. The main objective of this research was to compare three forms of extraction of potassium (nitro-perchloric decomposition, extraction with water and extraction with diluted solution of $\mathrm{HCl}$ ) of plant tissues samples of Tanzania grass (Panicum maximum cv. Tanzania) and alfalfa (Medicago sativa cv. Crioula). The methods of K extraction of Tanzania grass and alfalfa plant tissue samples in acid solution or diluted with water were equivalent to the traditional method of nitro-perchloric decomposition and can replace it.

Keywords: nitro-perchloric decomposition, $\mathrm{HCl} 1 \mathrm{~mol} \mathrm{~L}^{-1}$, water extraction,

\section{Referências}

[1] H. Marschner, Mineral nutrition of higher plants. Academic Press, New York, 1995. 889 p.

[2] E. Malavolta, G. C. Vitti, S. A. Oliveira, Avaliação do estado nutricional das plantas: princípios e aplicações. Potafos, Piracicaba: 2. ed. 1997.

[3] M. Würfels, E. Jackwerth, M. Stoeppler, Anal. Chim. Acta 226(1) (1989) 1.

[4] A. R. A. Nogueira, A. O. Matos, C. A. F. S. Carmo, D. J. Silva, F. L. Monteiro, G. B. Souza, G. V. E. Pita, G. M. Carlos, H. Oliveira, J. A. Comastri Filho, M. Miyazawa, W. Oliveira Neto, Tecido vegetal. In: A. R. A. Nogueira, G. B. Souza, (Ed.). Manual de laboratórios: solo, água, nutrição vegetal, nutrição animal e alimentos. Embrapa Pecuária Sudeste, São Carlos: 2005. p. 145-199.

[5] C. Carneiro, C.B. Reissmann, R. Marques. Cerne 12(2) (2006) 113.

[6] J. B. Jones Junior, V. W. Case, Sampling handling, and analyzing plant tissue samples. In: R. L. Westerman, J. V. Baird, N. W. Christensen, P .E. Fixen, D. A. Whitney, (Eds.). Soil testing and plant analysis. Soil Science Society of America Inc, Madison: 1990. p. 389-427. (SSSA Book Series, 3).

[7] M. Miyazawa, M. A. Pavan; M. F. M. Comm. Soil Sci. Plant Anal.15(1) (1984) 141.

[8] M.I. RADOMSKI, C. WINIEWSKI, Rev. Bras. Pl. Med., 6(3) (2004) 64.

[9] R. Heinrichs, E. Malavolta, Ci. Rural 31(5) (2001) 781.

[10] C. B. Reissmann, M. I. Radomski, R. M. B. Quadros, Arq Biol Tec (37)4 (1994) 959.

[11] M. Miyazawa, M. A. Pavan; M. F. M. Bloch, Ci. Cult. 36(4) (1884) 1953.

[12] F. J. Krug, Métodos de preparo de amostras; fundamentos sobre preparo de amostras orgânicas e inorgânicas para análise elementar. Ed. Francisco José Krug, Piracicaba: 2008.

[13] L. C. A. Melo, C. A. Silva, Quim. Nova 31(3) (2008) 556. 